\title{
Removal of Listeria monocytogenes Biofilm with Some Local Plant Extracts of Kurdistan Region, Iraq
}

\author{
Srwa A. Mohammed \\ Department of Medical Microbiology, Faculty of Science and Health, Koya University, Koya, KOY45, \\ Kurdistan Region - F.R. Iraq
}

\begin{abstract}
The results of removing or reducing biofilm were determined using subinhibitory concentrations (SICs) of some local plants in the flora of Kurdistan region of Iraq on biofilm production in Listeria monocytogenes. About $10-500 \mu \mathrm{g} / \mathrm{ml}$ of the plant extracts were used against growth and biofilm production in tissue culture plates which were measured spectroscopically. The SIC effects of each of Eugenia caryophyllata (Clove) and Rhus glabra (Sumac) have significantly affected on planktonic cells and reduced sessile cells or biofilm formation in $L$. monocytogenes. Remarkably, the data showed strong biofilm reduction under synergistically effect of the plant extract mixed with the antimicrobial agents in multidrugresistant $L$. monocytogenes. Whereas the SIC some of other plant extracts such as Salix candida and pomegranate (Punica granatum) have significantly enhanced biofilm expression in L. monocytogenes, but the use of these extracts synergistically with some antibiotics also resulted in inhibition of biofilm in comparison to merely use of either the extracts or antibiotics. The result of statistical analyses shows that $P>0.05$. The results showed that the combination of plant extract with antibiotic together has more effect than using plant merely.
\end{abstract}

Index Terms-Biofilm, Eugenia caryophyllata, Listeria monocytogenes, Salix candida.

\section{INTRODUCTION}

Biofilm is an organized aggregate of microorganisms living within an extracellular polymeric matrix that they produce and irreversibly attached to fetish or living surface which will not remove unless rinse quickly (Hurlow, et al., 2015).

Cell-to-cell communication is an important process, during which the required microbial cell density is attained. This leads to the secretion of signaling molecules, known as autoinducers. These autoinducers facilitate quorum sensing. At this stage of maturation, certain gene products are expressed that are considered important for the formation of extracellular polymeric substances (EPS). Since EPS is the main material in the biofilm's three-dimensional structure, interstitial voids are then produced in the matrix (Muhsin, et al., 2018).

ARO-The Scientific Journal of Koya University Volume VII, No.1(2019), Article ID: ARO.10385, 4 pages DOI: $10.14500 /$ aro. 10385

Received 21 January 2019; Accepted 10 August 2019

Regular research paper: Published 10 December 2019

Corresponding author's e-mail: srwa.ali@koyauniversity.org

Copyright (C) 2019 Srwa A. Hussein. This is an open-access article distributed under the Creative Commons Attribution License.
Biofilms occur on a wide variety of surfaces including living tissues, industrial equipment, and food processing surfaces such as conveyor belts, plastic, and stainless steel equipment. Since bacterial cells can be easily transferred from biofilms to food products, biofilms formed by pathogens such as Listeria monocytogenes are of particular concern for food industries. It has been demonstrated that L. monocytogenes can grow and form biofilms on several food processing surfaces including rubber, plastics, glass, and stainless steel. Biofilms of listeria protect cells from the action of antimicrobials and sanitizers, potentially allowing long-term persistence of the microorganism in the food processing environment (Giuseppe, et al., 2013).

Biofilm organisms have an inherent resistance to antibiotics, disinfectants, and germicides. The use of synthetic material for implantation is widely associated with "implant-associated infection" due to biofilm production. In the long run, they may be very damaging due to immune complex disease (Donlan and Costerton, 2002; García-Almendárez, et al., 2007).

Plant-derived compounds have gained widespread interest in the search to identify the alternatives for microbial control (Essawi and Srour, 2000). The compounds are widely accepted due to the perception that they are safe and have a long history of use in folk medicine for the prevention and treatment of diseases and infections (Guarrera, 2005). The present study was focused on using plant extracts at sub-minimum inhibition concentration (MIC) against the clinically relevant $L$. monocytogenes biofilms.

\section{Materials AND MethodS}

Twelve local plants used in this study. Some of them were obtained from Koya Haebatsultan and others from local market in Sulaimani city.

\section{A. Screening of Biofilm Production}

L. monocytogenes isolate that produce biofilm was received from Srwa, 2014, for the current study. Confirmation tests were done through colony morphology and biochemical tests. The isolate was subcultured and the control was prepared in tryptic soy broth (TSB) for $18 \mathrm{~h}$ at $37^{\circ} \mathrm{C}$. Before the experiments, the strain was vortexed for $5 \mathrm{~min}$ and the optical density adjusted to $1-1.5$ at $600 \mathrm{~nm}$ by spectrophotometer according to McFarland scale to the overnight culture was standardized to a concentration of $3 \times 10^{8} \mathrm{CFU} / \mathrm{ml}$. 
The strain diluted by obtaining $50 \mu \mathrm{l}$ of sample to $950 \mu \mathrm{l}$ broth aliquots of $200 \mu \mathrm{l}$ transferred to pre-sterilized, 96well polystyrene microtiter plates commercially available (Deltalab S.L., Spain), then incubated for $24 \mathrm{~h}$ at $37^{\circ} \mathrm{C}$. After incubation, discard the bacterial suspension totally each well was washed with $200 \mu$ l sterile phosphate buffer solution (PBS), then put on the hot plate for $1 \mathrm{~h}$ at $60^{\circ} \mathrm{C}$ for fixation, $25 \mu \mathrm{l}$ of $1 \%$ crystal violet was added to each well, after $15 \mathrm{~min}$ at room temperature, each well was washed with $200 \mu \mathrm{l}$ sterile PBS. The absorbance was determined at wavelength $450-630 \mathrm{~nm}$ in an enzyme-linked immunosorbent assay microtiter (Botic England). Controls were performed with crystal violet binding to the wells exposed only to the culture medium without bacteria (Bose, et al., 2009).

\section{B. Plants Classification}

The plants were classified by Dr. Eqbal Muhammed Xareb. She is assistant prof. in Koya University/Biology Department and her specialty is horticulture, apple leaves (Malus domestica), leaves of Quercus infectoria, leaves of bitter vetch (Lathyrus montanus), clove (Eugenia caryophyllata), and sumac (Rhus glabra), Portulaca oleracea, Vitis vinifera leaves, and Citrullus colocynthis, Anthemis tinctoria (Matricaria chamomilla), Salix candida, leaves Pistacia terebinthus, and pomegranate (Punica granatum).

\section{Preparation of Methanol Crude Extracts}

The plant samples were collected, and 12 plant extracts were prepared using absolute methanol; add $10 \mathrm{~g}$ of grinded plants to the conical flask. Then, $25 \mathrm{ml}$ of absolute methanol was added to the flask then placed in the refrigerator for 3 days. After $72 \mathrm{~h}$, the extracts were filtered through a Whatman filter paper No. $42(125 \mathrm{~mm})$ and it concentrated using a rotary evaporator (Laborota 4000, SN 090816862 , Germany) (Odey, et al., 2012). At the final step, the extracted was transferred into vials and stored at $4^{\circ} \mathrm{C}$.

\section{Determination of $M I C$}

The minimum inhibitory concentration (MIC) of medicinal plant extracts understudying was determined by turbidity method (spectrophotometric method) at $600 \mathrm{~nm}$, and the following dilutions were prepared for each extract $(10,20$, $30,40,50,60,70,80,100,200,300,400,500,600,700$, $800,1000$, and $1100 \mu \mathrm{M})$ (Ncube, et al., 2008), according to the plant activity, sub-MIC was adjusted. A stock solution of the extracts directly used without dilution, with the control of the bacterial suspension that prepared previously by two methods: $1-0.5 \mathrm{ml}$ of the bacterial suspension was put in the wells of the (96-well polystyrene microtiter) plates and the plant extracts was added directly and $2-0.5 \mathrm{ml}$ of the bacterial suspension of L. monocytogenes was put in the wells of the microtiter plate and was incubated for $24 \mathrm{~h}$ to allow set the sessile or biofilm formation. Then, it was mixed with the plant extracts at sub-MIC for each of the 12 extracts. Each well was compared with the control well (Djordjevic, et al., 2002).

\section{E. Susceptibility Test}

Antibiotic susceptibility test was conducted for biofilm that produces by L. monocytogenes isolate and was used eight extra high-performance liquid chromatography (Sigma) antimicrobials powder that has $100 \%$ activity. The bacterial strains were inoculated into TSB and incubated for $24 \mathrm{~h}$ at $37^{\circ} \mathrm{C}$ to allow forming biofilm; then, MIC of antimicrobial agents was added to microwells after discard the bacterial suspension (NCCLS, 2000). The antimicrobial agents that were used [ampicillin (AMP), chloramphenicol (CHL), nalidixic acid (NAL), Rifampin (RIF), Tetracycline (TET), Carbincillin (CAR), Streptomycin (STR), and neomycin (N)].

\section{F. Combination Effect of Antimicrobial Agents with Some Effective Plants on Biofilm}

The extracts at sub-MIC were mixed with antimicrobial agents at sub-MIC in sterile Eppendorf tubes. The mixtures were transferred into the wells of the 96 microtiter plates which contain biofilm of L. monocytogenes isolate, to determine the nature of the interactions between the extracts and antimicrobial agents using Equation 1 (Srwa and Shwan, 2017).

$$
\frac{M I C_{x y} \text { in combination }}{M I C_{x} \text { alone }}+\frac{M I C_{x y} \text { in combination }}{M I C_{y} \text { alone }}
$$

\section{G. Statistical Analyses}

$\mathrm{Z}$ score was done for double OD before $10 \mathrm{~h}$ incubation and after $10 \mathrm{~h}$ incubation. The result was 1.58 from $\mathrm{Z}$ score and $P=0.11$. The result shows that $P>0.05$ (Richard and Morris, 2000).

\section{Results AND Discussion}

\section{A. Reducing Biofilm Formation in L. monocytogenes by 12 Different Types of Plant Extract}

Twelve different types of plant extract were screened for their antimicrobial activities against both planktonic and sessile or biofilm bacteria. First method: The extracts were initially tested on planktonic microorganisms using the MIC assay. The results showed clove (E. caryophyllata), A. tinctoria ( $M$. chamomilla), S. candida, leaves $P$. terebinthus, and sumac (R. glabra); crude extracts have good effect on inhibiting $L$. monocytogenes. About $0.5 \mathrm{ml}$ of the bacterial suspension from control sample was mixed with the crude methanol plant extracts $10,40,80$, 500 , and $500 \mu \mathrm{l} / \mathrm{ml}$, respectively, and incubating overnight, then culturing on nutrient agar. The results show no growth isolated for each of them. Meanwhile, some of the extracts can be used such as supportive media or such as nutrient for bacteria. The study of Nyila, et al., 2012 used 13 different sorts of plant extract against $L$. monocytogenes planktonic cells and showed that epigallocatechin was found to be active against L. monocytogenes at a concentration of $0.062 \mathrm{mg} / \mathrm{ml}$. While, (Nzeako and Lawati, 2008) used thyme and clove essential oils as antifungal agents and showed growth inhibitions of more than $25 \mathrm{~mm}$ (diameter) up to 1:16 
dilution. And showed the minimum fungicidal concentration (MFC) of thyme and clove for all the organisms were $1.9 \mathrm{x}$ $10^{3} \mu \mathrm{g} / \mathrm{mL}$ for thyme and $2.5 \times 10^{3} \mu \mathrm{g} / \mathrm{mL}$ for clove. Second method: Treating L. monocytogenes that produce biofilm with 12 different types of plant extracts were tested on sessile cells or biofilm formation after incubating for $24 \mathrm{~h}$ and set the biofilm. The results are shown in Fig. 1.

Fig. 1 shows the effect of crude methanol extracts of $Q$. infectoria leaves, leaf of bitter vetch (L. montanus), bark of clove (E. caryophyllata), and seed of sumac (R. glabra). In the well (A3, A9, A11, and C8) $(0.191,0.181,0.284$, and 0.178 , respectively), they have good effects on reducing biofilm that produces by $L$. monocytogenes, by adding 35 , 35,8 , and $8 \mu \mathrm{l}$, respectively, of the extracts at sub-MIC in the prepared well previously by adding bacterial suspension and incubating for $24 \mathrm{~h}$ till biofilm set by tested isolate and discard the suspension just remain biofilm in the wells. The results were read by ELIZA and well A1 shows control of L. monocytogenes OD reading was 1.192 .

On the other hand, some of the plant extracts enhance or increase biofilm formation such as $P$. oleracea, $S$. candida, P. granatum, V. vinifera leaves, and C. colocynthis in the A4, $\mathrm{B} 6, \mathrm{~B} 9, \mathrm{C} 1$, and $\mathrm{C} 2$, respectively, and OD reading for each of them was $3.22,2.50,2.34,5.60$, and 6.32 , respectively, as shown in Fig. 1. The present study in accordance with the study of Sandasi, et al., 2010, used 16 different types of plant including clove against three pathogenic microorganisms (L. monocytogenes, Pseudomonas aeruginosa, and Candida albicans), but peppermint was the only extract that showed the best antibiofilm activity against all the tested organisms on a preformed biofilm and also showed that the inhibition of growth of a preformed biofilm was more difficult to achieve resulting in most of the extracts enhancing the growth of the biofilms. Furthermore, the study of Nyila, et al., 2010, showed listerial biofilms, treated with Syzygium aromaticum or Mentha spicata essential oils, and exhibited the same biomass (absorbance 0.09) as that of the positive control (ciprofloxacin). It was, therefore, assumed that the antilisterial activity of these essential oils could be attributed to the activity of their major chemical constituents, eugenol, and carvone. However, surprisingly, these compounds alone caused biofilm enhancement rather than inhibition.

\section{B. Susceptibility Test}

Susceptibility test was conducted for biofilm that produces by $L$. monocytogenes, eight widely antimicrobials at final concentration were used (AMP, NAL, N, STR, CHL, RIF, TET, and CAR) in well (A1, A2, A3, A4, A5, A6, A7, and A8, respectively), which demonstrated in Fig. 2. OD reading of biofilm that produces by L. monocytogenes was 1.195 , but when exposed to the antibacterial agents, the relative activity of the biofilm was markedly higher than that in single-species biofilms and the optical density reading of biofilm was $1.439,1.293,1.164,1.144,1.163,1.171,1.104$, and 1.092, respectively, as shown in Table I. The study of Burmølle, et al., 2006, was found to interact synergistically in biofilms formed in 96-well microtiter plates: Biofilm biomass was observed to increase by $>167 \%$ in biofilms formed by the four strains compared to biofilms composed of single strains.

TABLE I

Susceptibility Test for Biofilm that DeVeloped by Listeria MONOCYTOGENES ISOLATE

\begin{tabular}{lccccccccc}
\hline \hline Isolate & Control & AMP & NAL & N & STR & CHL & RIF & TET & CAR \\
\hline $\begin{array}{l}\text { Listeria } \\
\text { monocytogenes }\end{array}$ & A9 & A1 & A2 & A3 & A4 & A5 & A6 & A7 & A8 \\
& 1.192 & 1.439 & 1.293 & 1.164 & 1.144 & 1.163 & 1.171 & 1.151 & 1.092 \\
\hline \hline
\end{tabular}

AMP: Ampicillin, NAL: Nalidixic acid, N: Neomycin, STR: Streptomycin,

CHL: Chloramphenicol, RIF: Rifadin, TET: Tetracycline, CAR: Carbenicillin

TABLE II

The Effects of Combination Antibiotics and Some Plant Extracts on Biofilm Produced by ListerIa MONOCYTOGENES

\begin{tabular}{lccccc}
\hline $\begin{array}{l}\text { Listeria } \\
\text { monocytogenes }\end{array}$ & RIF & TET & STR & N & AMP \\
\hline $\begin{array}{l}\text { Clove } \\
\text { Pomegranate }\end{array}$ & B1 0.155 & B2 0.192 & B3 0.108 & B5 0.111 & B11 0.179 \\
$\begin{array}{l}\text { Sumac (Rhus } \\
\text { anacardiaceae) }\end{array}$ & A12 0.253 & B12 0.182 & C1 0.118 & C2 0.177 & C3 0.112 \\
\begin{tabular}{l} 
Salix candida \\
\hline \hline
\end{tabular} & C6 0.075 & C7 0.055 & C8 0.056 & C9 0.091 & C5 0.065 \\
\hline
\end{tabular}

RIF: Rifadin, TET: Tetracycline, STR: Streptomycin, N: Neomycin, AMP: Ampicillin

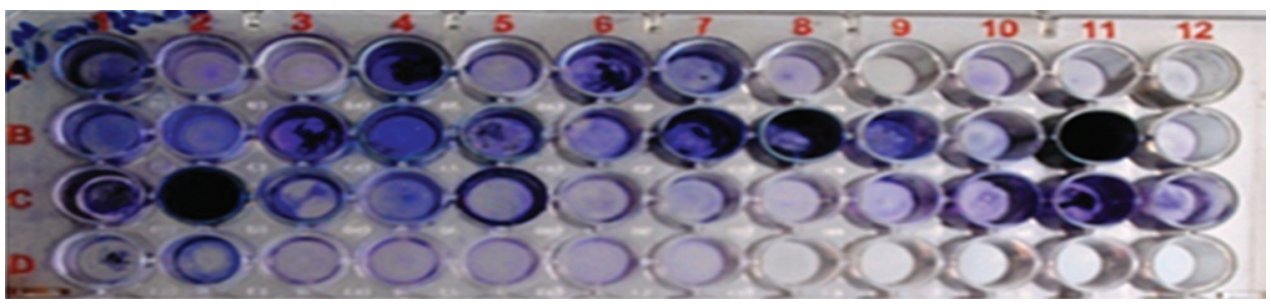

Fig. 1. Treating Listeria monocytogenes biofilm with 12 different types of plant extracts.

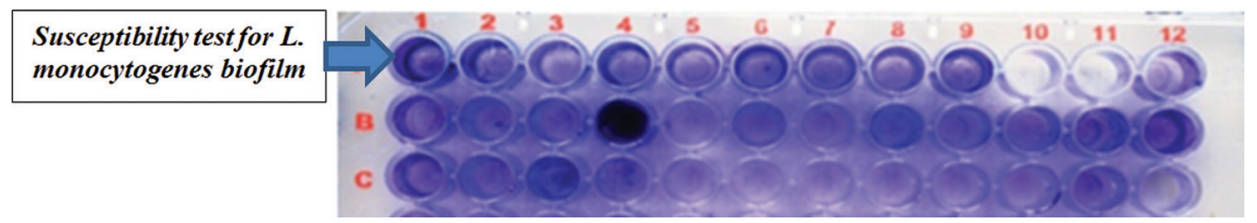

Fig. 2. Treating Listeria monocytogenes biofilm with antimicrobial agents and mixed (antimicrobial agents with plant extracts). 
When exposed to the antibacterial agent hydrogen peroxide or TET, the relative activity (exposed versus non-exposed biofilms) of the four-species biofilm was markedly higher than that in any of the single-species biofilms.

\section{Treating L. monocytogenes Biofilm with Mixed Antimicrobial Agents and Plant Extracts}

Combination of five different sorts of antimicrobial agents mixed with three different plant extracts such as clove (E. caryophyllata), pomegranate, sumac ( $R$. glabra), and $S$. candida separately. They have good effects on reducing biofilm as shown in Fig. 2. The OD reading for each of them demonstrates in Table II. The present study showed synergistic activity between antimicrobial agents and these plant extracts and this agrees with the study of Srwa and Shwan, 2017 showed in their study synergistic activity between plant extracts and antimicrobial agents on biofilm produced by Klebsiella pneumonia.

In general, sumac (Rhus anacardiaceae) and clove (E. caryophyllata) were the only two extracts with low concentration showed good antibiofilm activity and good antibacterial activity against $L$. monocytogenes, while some of the extracts enhanced bacterial activity and biofilm development. And the use of these extracts synergistically with some antibiotics also resulted in inhibition of biofilm in comparison to merely use of either the extracts or antibiotics. There is little study about reducing biofilm by traditional herbs or plants, while many researches nowadays carried out about inhibition of bacterial activity.

\section{CONCLUSION}

The results show that the reduction of biofilm mass using plant extracts has good effect, but using the combination of plant and antibiotic together has more effect than using plant solely.

\section{ACKNOWLEDGMENTS}

We would like to express our deepest and warmest gratitude to the entire members in Science and Health Research Center (SHRC) of Koya University for their help and kindness.

\section{REFERENCES}

Bose, S., Khodke, M., Basak, S., and Malick, S.K., 2009. Detection of biofilm producing staphylococci: need of the hour. Journal of Clinical and Diagnostic Research, 3(6), pp.1915-1920.

Burmølle, J.S.W., Dhana R., Lars H.H., Søren J.S.M., and Staffan, K., 2006. Enhanced Biofilm formation and increased resistance to antimicrobial agents and bacterial invasion are caused by synergistic interactions in multi species biofilms. Journal of American Society for Microbiology Applied and Environmental
Microbiology, 72(6), pp.3916-3923.

Djordjevic, D., Wiedmann, M., and Mclandsborough, L.A., 2002. Microtitre plate assay for assessment of Listeria monocytogenes biofilm formation. Applied and Environmental Microbiology, 68(6), pp.2950-2958.

Donlan, R.M., and Costerton, W., 2002. Biofilms: Survival mechanisms of clinically relevant microorganisms. Clinical microbiological Review, 15(2), pp.167-193.

Essawi, T., and Srour, M., 2000. Screening of some palestinian medicinal plants for antibacterial activity. Journal Ethnopharmacology, 70(3), pp.343-349.

García-Almendárez, B.E., Cann, I.K.O., Martin, S.E., Guerrerro-Legrreta, I., and Regalado, C., 2007. Effect of Lactococcus lactis UQ2 and its bacteriocin on Listeria monocytogenes biofilms. Food Control, 19, pp.670-680.

Giuseppe, B., Russo, P., Capozzi, V., Amodio, M.L., Giuseppe, S., and Luciano, B., 2013. Listeria monocytogenes, biofilm formation and fresh cut produce. Food and Environmental Sciences, pp.114-123.

Guarrera, P.M., 2005. Traditional phytotherapy in central Italy (Marche, Abruzzo, and Latium). Fitoterapia, 76(1), pp.1-25.

Hurlow, J., Couch, K., Laforet, K., Bolton, L., Metcalf, D., and Bowler, P., 2015. Clinical biofilms: A challenging frontier in wound care. Adv Wound Care, 4, pp.295-301.

Muhsin, J., Wisal, A., Saadia, A., Fazal, J., Muhammad, I., Muhammad, A.N., Tahir, H., Muhammad, A., Muhammad, R., and Muhammad, A.K., 2018. Bacterial biofilm and associated infections. Journal of the Chinese Medical Association, 81(1), pp.7-11.

National Committee for Clinical Laboratory Standards (NCCLS). 2000. Methods for Dilution Antimicrobial Susceptibility Tests for Bacteria that Grow Aerobically. National Committee for Clinical Laboratory Standards, Wayne, PA.

Ncube, N.S., Afolayan, A.J., and Okoh, A.I., 2008. Assessment techniques of antimicrobial properties of natural compounds of plant origin: Current methods and future trends. African Journal of Biotechnology, 7(12), pp.1797-1806.

Nyila, M.A., Leonard, C.M., Hussein, A.A., and Lall, N., 2012. Activity of South African medicinal plants against Listeria monocytogenes biofilms, and isolation of active compounds from Acacia karroo. South African Journal of Botany, 78, pp.220-227.

Nzeako, B.C., and Lawat, B.A., 2008. Comparative studies of antimycotic potential of thyme and clove oil extracts with antifungal antibiotics on Candida albicans. African Journal of Biotechnology, 7(1), pp.1612-1619.

Odey, M.O., Iwara, I.A., Udiba, U.U., Johnson, J.T., Inekwe, U.V., Asenye, M.E., and Victor, O., 2012. Preparation of plant extracts from indigenous medicinal plants. International Journal of Science and Technology, 1(12), pp.688-692.

Richard, J.L., and Morris, L.M., 2000. An Introduction to Mathematical Statistics and its Applications. $3^{\text {rd }}$ ed. Prentice-Hall, New Jersey, p.282.

Sandasi, M., Leonard, C.M., and Viljoen, A.M., 2010. The in vitro antibiofilm activity of selected culinary herbs and medicinal plants against Listeria Monocytogenes. Letters in Applied Microbiology, 50(1), pp.30-5.

Srwa, A.M., 2014. Biofilm determination of Listeria monocytogenes that isolated from different sources. Journal of Life Science, 8(10), pp.1-5.

Srwa, A.M., and Shwan, K.R., 2017. Inhibition of biofilmi production in multidrug resistant Klebsiella pneumonia by extract of some plants in the flora of Koya city. Proceedings ICNS Charmo Journal, 2, pp.60-67. 